\title{
A Photochromic Copolymer Hydrogel Contact Lens: From Synthesis to Application
}

\author{
Xiaoli Yang, Limin Huang, Lihua Zhou, Hao Xu, and Zihan Yi \\ School of Material Engineering, Jinling Institute of Technology, Nanjing 211169, China \\ Correspondence should be addressed to Xiaoli Yang; yangxl@jit.edu.cn
}

Received 27 June 2016; Revised 8 September 2016; Accepted 22 September 2016

Academic Editor: Xiao Gong

Copyright ( 2016 Xiaoli Yang et al. This is an open access article distributed under the Creative Commons Attribution License, which permits unrestricted use, distribution, and reproduction in any medium, provided the original work is properly cited.

\begin{abstract}
A photochromic poly(2-hydroxyl-ethyl methacrylate-N-vinylpyrrolidone-spironaphthoxazine) hydrogel (p(HEMA-NVP-SPO)) has been designed and synthesized by free radical polymerization in this work. The chemical and structural information of hydrogels was investigated by IR spectra, equilibrium water content (EWC), and SEM. The IR spectra confirmed successful synthesis of copolymer. The domain of NVP contributed to not only EWC but also inner structure of hydrogel, while SPO had little influence on these properties of hydrogel. The photochromic behaviors of hydrogel including photochromic properties and thermal fading kinetics were systematically studied and compared with hydrogel made by immersing method. Results showed that when SPO was incorporated in hydrogel by polymerization, maximum absorbance wavelength got shorter, and the relaxation half-life became longer. In addition, salicylic acid as a drug model could be loaded into hydrogel by immersing method, and its sustained drug release in a given period was dependent on the characteristics of solution and loading time.
\end{abstract}

\section{Introduction}

Photochromic materials can change their color after being triggered by certain light due to a reversible structural transformation of chemical [1-3]. Spironaphthoxazine (SPO) based materials have attracted increasing interest due to their remarkable photochromic properties, such as excellent photostability, compatibility in various matrices, and high fatigue resistance [4-7]. These advantages enhance the practical applicability of SPO in optical systems for registration and storage [8], molecular switches [9], and UV sensors [10]. The photoresponsive site of the SPO comes from the center $\mathrm{sp}^{3}$ spiro carbon. Upon UV irradiation, the carbonoxygen bond cleaves and achieves $\mathrm{sp}^{2}$ hybridization, yielding an open planar merocyanine (MC), which is metastable and readily isomerizes $[11,12]$. So it can revert back to the spiro form via ring closing when irradiated with visible light or thermal radiation. We have previously synthesized a series of SPO derivatives and investigated their photochromic behaviors and thermal stability in different films [13]. All the compounds exhibited excellent photochromic properties upon UV irradiation. And their relaxation time was in a broad range (from 129 to 1724 s). On account of these merits, SPO was introduced into hydrogel contact lens in this work, aiming at endow contact lens with photochromic properties.

As far as contact lens was concerned, hydrogel is a leading material of contact lens due to its good transparency, which satisfied the optic requirement of contact lens [14]. Moreover, hydrogel had a water swollen structure, which can mimetic nature biological environment. Thus, generally, hydrogel possesses good biocompatibility $[15,16]$. Traditional hydrogel contact lens is polymerized by 2-hydroxyl-ethyl methacrylate (HEMA), but a number of problems restricted its application like low oxygen permeability, limited hydrophilicity, and poor antibacterial properties. Recently, some measures had been taken to improve these problems including copolymerizing with hydrophilic monomer [17], introducing chitosan to hydrogel network [18], and modifying surface via layer-by-layer assembly [19-21]. Further, in order to realize certain functions like drug delivery function, other functional monomers such as cyclodextrin $(\mathrm{CD})$ had been introduced into contact lens by copolymerization $[22,23]$, by surface functionalization [24], or by nanocomposite technology [25]. Although the 
abovementioned researches had made considerable progress, they did not refer to photochromic contact lens.

In this work, we attempted to introduce SPO into hydrogel contact lens by polymerization, investigate their properties, and explore their application. In order to improve the hydrophilicity, vinylpyrrolidone (NVP) has also been added. As a control, SPO blended hydrogel contact lens was also prepared.

\section{Experimental}

2.1. Materials. Hydroxyethyl methacrylate (HEMA) and $\mathrm{N}$-vinylpyrrolidone (NVP) were obtained from Shanghai Jingchun Industries Co. Ltd., China, and distilled under vacuum before use. 2,2-Azobis(isobutyronitrile) (AIBN) was recrystallized from methanol. All other chemicals were analytically pure and were employed without any further drying or purification.

Phosphate buffered saline (PBS) ( $\mathrm{pH} 7.2$ ) solution is as follows: $137 \mathrm{mmol} \mathrm{L}^{-1} \mathrm{NaCl}, 2.7 \mathrm{mmol} \mathrm{L}^{-1} \mathrm{KCl}, 10 \mathrm{mmol} \mathrm{L}^{-1}$ $\mathrm{Na}_{2} \mathrm{HPO}_{4}$, and $2 \mathrm{mmol} \mathrm{L}^{-1} \mathrm{KH}_{2} \mathrm{PO}_{4}$. Artificial tear solution (ATS) is as follows: $2.18 \mathrm{~g} \mathrm{~L}^{-1} \mathrm{NaHCO}_{3}, 6.78 \mathrm{gL}^{-1} \mathrm{NaCl}$, $0.084 \mathrm{~g} \mathrm{~L}^{-1} \mathrm{CaCl}_{2}$, and $1.38 \mathrm{~g} \mathrm{~L}^{-1} \mathrm{KCl}$.

2.2. Synthesis of Spironaphthoxazine (SPO) Monomer. The synthetic methods for the photochromic SPO monomer of 1,3,3-trimethyl-9' -methacryloyloxy-spiro[indoline$2,3^{\prime}(3 \mathrm{H})$ naphtho[2,1-b] $[1,4]$ oxazine] were adopted and modified from previously published procedure [26]. Grey solid, yield: $97.4 \%$, m.p. $151-153^{\circ} \mathrm{C}$ (melting point apparatus, Taike, China). IR (IS10, $\mathrm{KBr}, \mathrm{cm}^{-1}$ ): 3048, 2972, 1730, 1628, 1480, $1440,1360,1257,1080,1170,1118,978,902,823,745 .{ }^{1} \mathrm{H}$ NMR $\left(\mathrm{CDCl}_{3}, \mathrm{AV}-500\right): \delta 8.26(1 \mathrm{H}, \mathrm{d}, J=2.3 \mathrm{~Hz}, \mathrm{ArH}), 7.77(1 \mathrm{H}$, $\mathrm{d}, J=8.9 \mathrm{~Hz}, \operatorname{ArH}), 7.73\left(1 \mathrm{H}, \mathrm{s}, 2^{\prime}-\mathrm{H}\right), 7.66(1 \mathrm{H}, \mathrm{d}, J=8.9 \mathrm{~Hz}$, ArH), 7.24-7.17 (2H, m, ArH), 7.08 (1H, d, $J=7.1 \mathrm{~Hz}, \operatorname{ArH})$, $6.98(1 \mathrm{H}, \mathrm{d}, J=8.9 \mathrm{~Hz}, \mathrm{ArH}), 6.90(1 \mathrm{H}, \mathrm{t}, J=7.4 \mathrm{~Hz}, \mathrm{ArH})$, $6.56(1 \mathrm{H}, \mathrm{d}, J=7.7 \mathrm{~Hz}, \mathrm{ArH}), 6.39(1 \mathrm{H}, \mathrm{s}, \mathrm{CH}), 5.77(1 \mathrm{H}, \mathrm{s}$, $\mathrm{CH}), 2.74\left(3 \mathrm{H}, \mathrm{s}, \mathrm{CH}_{3}\right), 2.10\left(3 \mathrm{H}, \mathrm{s}, \mathrm{CH}_{3}\right), 1.36\left(6 \mathrm{H}, \mathrm{s}, \mathrm{CH}_{3}\right)$. Anal. calcd. for $\mathrm{C}_{26} \mathrm{H}_{24} \mathrm{~N}_{2} \mathrm{O}_{3}$ : C, 75.71; $\mathrm{H}, 5.86 ; \mathrm{N}, 6.79$. Found C, 75.58; H, 5.84; N, 6.80\%.

\subsection{Synthesis of Photochromic Hydrogels}

Polymerization Method. Monomers ( $5 \mathrm{~mL}$ ) of HEMA, NVP, and SPO were mixed by stirring, in which certain amount of AIBN was added into the mixture. This mixture was injected into the model ( $150 \mu \mathrm{m}$ thickness), which then was put into the oven for 3 hours at $70^{\circ} \mathrm{C}$; the reaction mixture was brought to room temperature, filtered, and rinsed with ethanol five times to remove all chemicals and nonconjugated monomer. The product was dried in vacuum. In addition, the feed composition and the samples code of the hydrogels are listed in Table 1.

Immersing Method. The $\mathrm{p}$ (HEMA-NVP) hydrogels were obtained by using the polymerization method above and then were immersed in ethanol solution $(5 \mathrm{~mL})$, in which the concentration of SPO was 3\%. The samples were kept
TABle 1: Composition of initial reaction mixtures used for the preparation of polymer hydrogels.

\begin{tabular}{lc}
\hline Hydrogels & $\begin{array}{c}\text { Mass ratio }(\%) \\
\text { HEMA : NVP : SPO }\end{array}$ \\
\hline Hydrogel 1 & $100: 0: 0$ \\
Hydrogel 2 & $75: 25: 0$ \\
Hydrogel 3 & $60: 40: 0$ \\
Hydrogel 4 & $60: 40: 3$ \\
\hline
\end{tabular}

undisturbed at room temperature for a week; the resulting films were kept in dark before measurement.

2.4. Characterization of Photochromic Hydrogels. The formed hydrogels were characterized by IR spectrum (IS10). Each hydrogel was freeze-dried at $-50^{\circ} \mathrm{C}$ and then characterized by scanning electron microscopy (SEM, SU8010).

The hydrogels were dried and weighed $\left(W_{0}\right)$. The hydrogels were weighed $\left(W_{1}\right)$ after dry hydrogels had been submerged in distilled water at $37^{\circ} \mathrm{C}$ for $24 \mathrm{~h}$. Equilibrium water content of the hydrogels was defined as $\operatorname{EWC}(\%)=\left(W_{1}-\right.$ $\left.W_{0}\right) / W_{1} \times 100 \%$.

Optical absorption spectra were recorded using UV spectrum (CARY 50). The sample was first irradiated with a $40 \mathrm{~W}$ ultraviolet lamp $(365 \mathrm{~nm})$ and then reverse irradiated with visible light. The process was repeated for 20 cycles. The intervals were $10 \mathrm{~min}$.

The kinetics of the thermal discoloration were recorded following the color bleaching of the irradiated sample at $\lambda_{\text {max }}$, immediately after switching off the ultraviolet lamp. The discoloration dynamic at $\lambda_{\text {max }}$ was fitted by the following equation [27]:

$$
\ln \left(\frac{A_{t}-A_{\infty}}{A_{0}-A_{\infty}}\right)=-k \cdot t,
$$

where $A_{0}, A_{t}$, and $A_{\infty}$ are the absorbencies at zero, times, and infinity respectively.

For salicylic acid release experiment, an amount of $5 \mathrm{mg}$ of salicylic acid model drug was dissolved in $100 \mathrm{~mL}$ water or buffered solution (PBS, ATS); then, $20 \mathrm{mg}$ hydrogels were submerged into the solution to load drug. After $24 \mathrm{~h}$ at $37^{\circ} \mathrm{C}$, the absorbance of salicylic acid was measured by UVVis spectrophotometer (Varian, Vary 50) at $\lambda_{\max }=279 \mathrm{~nm}$ and compared with a standard curve. The salicylic acid concentration after loading was obtained by the difference of concentration and volume before and after immerging. The cumulative release rate in hydrogel was calculated by the difference of salicylic acid concentration before and after loading.

\section{Results and Discussion}

3.1. Synthesis and Fundamental Characterization of Hydrogels. The FTIR spectra of hydrogels were shown in Figure 1. In case of PHEMA (hydrogel 1), a broad band that appeared at $3440 \mathrm{~cm}^{-1}$ was attributed to hydrogen-bonded $\mathrm{OH}$ group. The strong peak at $1720 \mathrm{~cm}^{-1}$ showed ester carbonyl group 


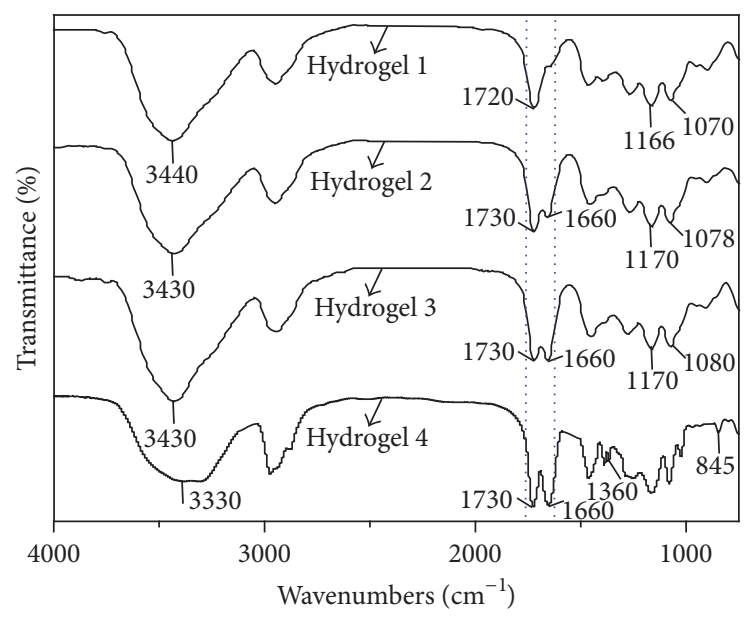

FIgURE 1: The IR spectra of hydrogels.

$(\mathrm{C}=\mathrm{O})$. The peaks at 1166 and $1070 \mathrm{~cm}^{-1}$ were associated with the stretching vibrations of $\mathrm{C}-\mathrm{O}$ [28]. Compared to the IR spectrum of pHEMA, p(HEMA-NVP) (hydrogel 2 and hydrogel 3) showed a new peak at around $1665 \mathrm{~cm}^{-1}$, corresponding to the carbonyl stretching banding of NVP [29]. With increasing NVP content, this characteristic absorption band was strengthened, which further confirmed the presence of NVP in the hydrogels. In the spectrum of p(HEMA-NVP-SPO) (hydrogel 4), the new absorption bands at $1360 \mathrm{~cm}^{-1}$ and $845 \mathrm{~cm}^{-1}$ were attributed to the stretching vibration of $\mathrm{Ar}-\mathrm{N}$ and the stretching vibration outside surface of $=\mathrm{C}-\mathrm{H}$ in $\mathrm{SPO}$, respectively. Furthermore, characteristic bands at around $900 \mathrm{~cm}^{-1}$ and $3100 \mathrm{~cm}^{-1}$ corresponding to the vinyl groups of monomers disappeared completely, which indicated nonexistence of unreacted monomers. These well supported the successful entry of SPO moieties into the network formation of hydrogels [30].

The equilibrium water content (EWC) of the hydrogels was also studied (Figure 2). As it can be seen, all hydrogels exhibited EWC values greater than $30 \%$ in distilled water, which belong to the soft contact lens materials. In the case of the p(HEMA-NVP) hydrogels (hydrogel 2 and hydrogel 3), EWC values were observed to increase from about $47 \%$ to $61 \%$ with the increase of the NVP content. In contrast, the pure pHEMA hydrogel (hydrogel 1) showed a minimum EWC value about $34 \%$. NVP was more hydrophilic than HEMA; hence, when increasing NVP content, the hydrogel networks became more hydrophilic and then absorbed more water. Moreover, the adding of a small amount of SPO had nearly no influence upon EWC of hydrogels. It is noted that the hydrogels showed a lower EWC in the presence of PBS than in distilled water. This might be attributed to the change of osmotic pressure [31]. Compared with water, the higher salt concentration in PBS decreased the osmotic pressure difference between hydrogel network and external solution, which prevented water molecules from penetrating into the hydrogels.

The interior morphologies of the freeze-dried hydrogels were shown in Figure 3. The pure pHEMA hydrogel

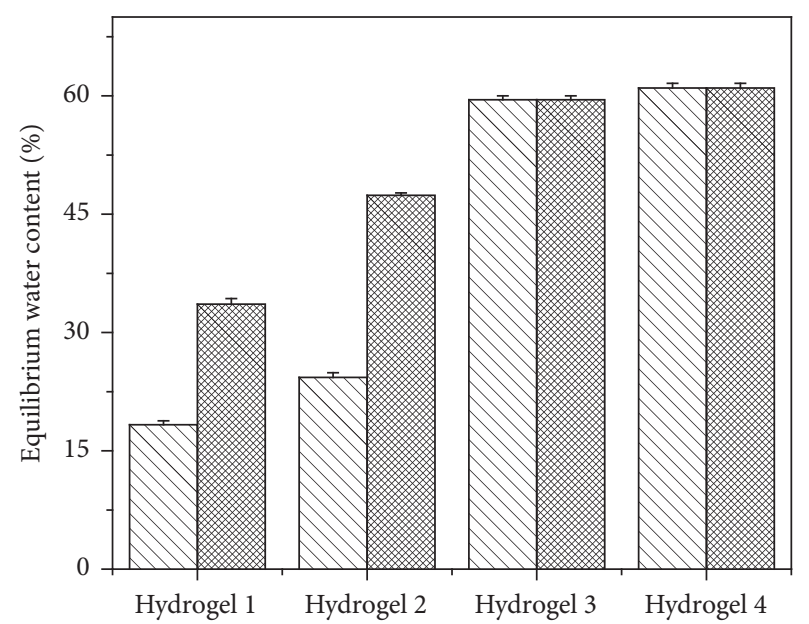

PBS
Distilled water

FIGURE 2: The equilibrium water content of hydrogels.

presented a continuous and even morphology without pores (hydrogel 1). In contrast, the pHEMA-NVP hydrogel exhibited a highly interconnected porous structure (hydrogel 2 and hydrogel 3). It was observed that hydrogel 3 had larger average pore size $(24 \pm 10 \mu \mathrm{m})$ than hydrogel $2(16 \pm 3 \mu \mathrm{m})$ due to the increasing of NVP content. This trend might be related to relative larger free volume of NVP owing to the existence of five-membered ring, which prevented the collapse of linear chain in the freeze-drying process, resulting in larger pore size. p(HEMA-NVP-SPO) hydrogel (hydrogel 4) was similar to that of hydrogel 3, indicating little influence of SPO on the morphology. This might be attributed to very small content of SPO in hydrogel.

\subsection{Photochromic Performance and Thermal Fading Kinetics.} Electronic absorption spectral changes of two hydrogels made by immersing method and by polymerization method are depicted in Figure 4, insets of which show the color changes of photochromic hydrogel before and after UV light; nearly colorless hydrogels turned to blue after being irradiated with UV light and then converted back to that of the initial color under visible light irradiation. The absorption spectrums were broad in both hydrogels; this was mainly related to the coloring mechanism. After UV illumination, bond breakage in the excited spiro form on SPO occurred; the intermediate $\mathrm{X}$ was produced first, which then decayed into zwitterionic merocyanines, because the merocyanines were mixture of at least four isomers and their optical spectrums were broad absorption bands [32]. We observed that UV irradiation of the hydrogel made by immersing method at $365 \mathrm{~nm}$ led to the maximum absorbance $\left(\lambda_{\max }\right)$ at $620 \mathrm{~nm}$ (Figure 4(a)), while in the hydrogel made by polymerization method there was a shift in $\lambda_{\max }$ to a shorter wavelength, which was $610 \mathrm{~nm}$ (Figure 4(b)). This blue shift presumably indicated that the interaction modes of SPO and HEMENVP affected the UV absorption of hydrogel. When SPO took part in polymerization reaction, main chain of copolymer 

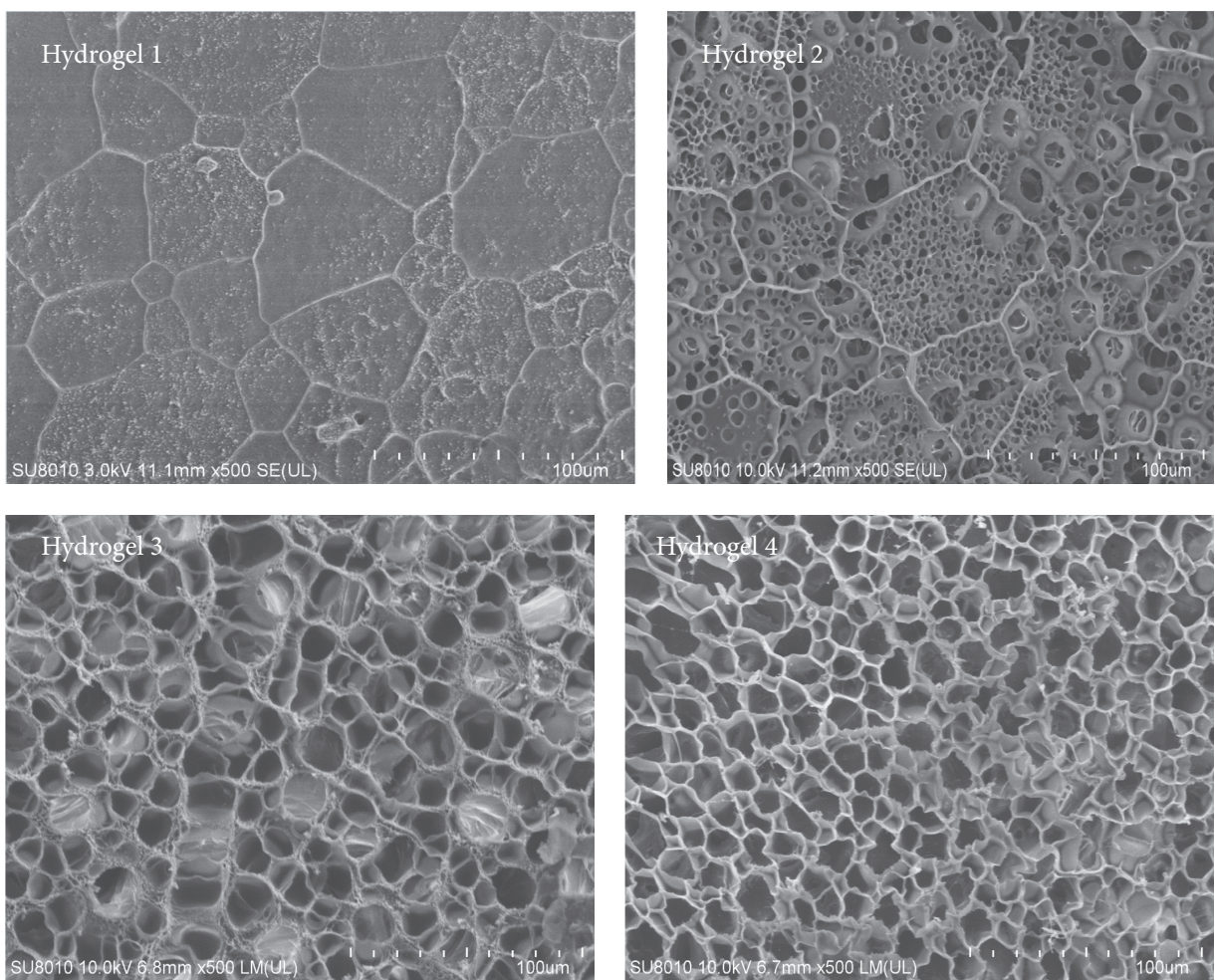

FIgURe 3: SEM images of hydrogels.

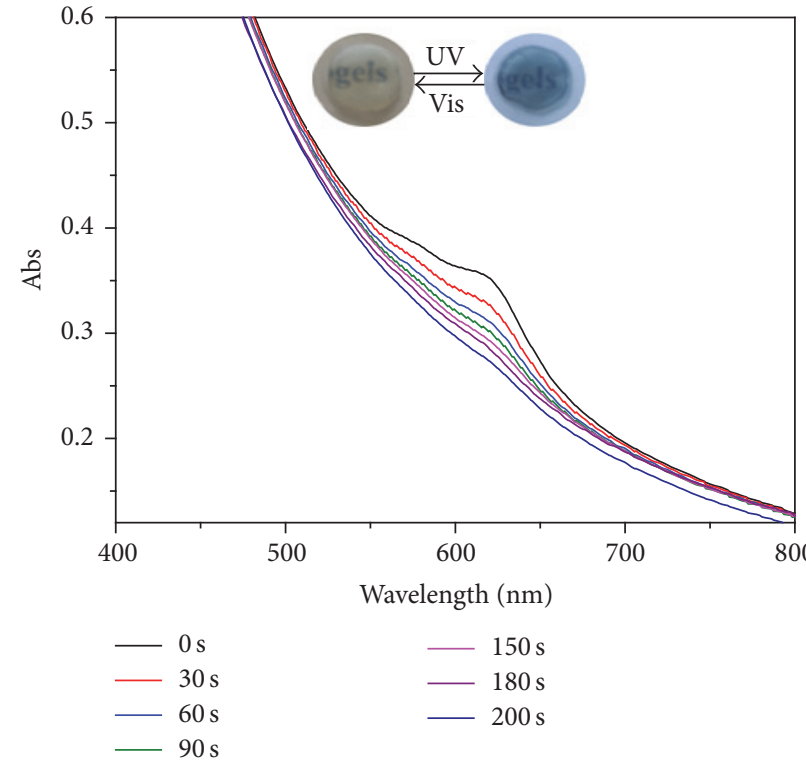

(a)

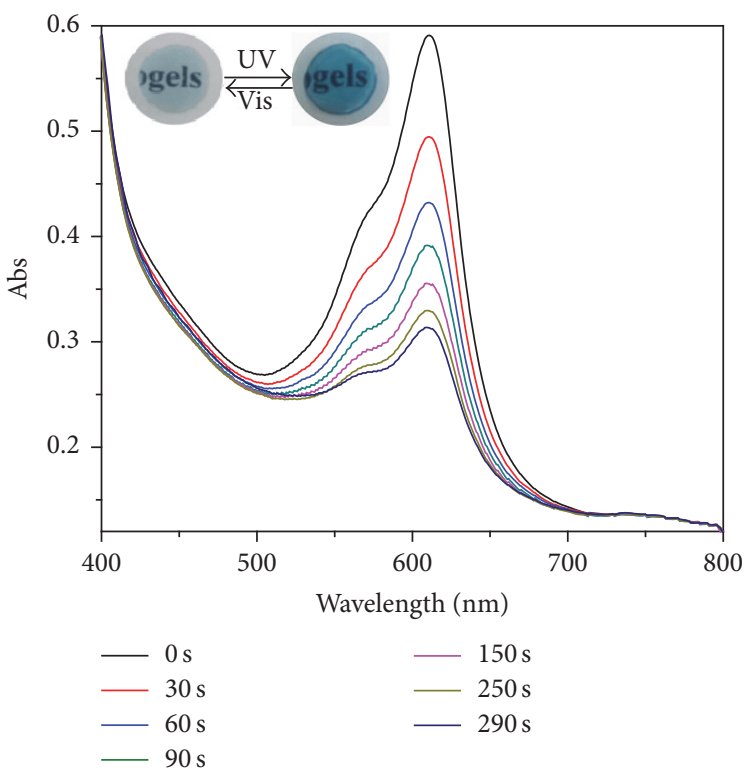

(b)

FIGURE 4: Absorption spectra with irradiation time for (a) immersing method and (b) polymerization method.

became the modified group of $9^{\prime}-\mathrm{C}$ on SPO, increasing the steric hindrance around it, which led to the blue shift of the absorption [33].

Figure 5 shows the thermal fading of photochromic hydrogels in which the MC absorbance at $\lambda_{\max }(620 \mathrm{~nm}$, immersing method; $610 \mathrm{~nm}$, polymerization method) was recorded immediately after termination of the UV irradiation. The overall thermal closing in both hydrogels was evaluated to obey the first-order kinetics as the plots of $\ln \left(A_{t}-A_{\infty}\right) /\left(A_{0}-A_{\infty}\right)$ were linear. The corresponding relaxation time of the MC isomer ( $\tau \mathrm{MC}$-SPO) was obtained $t$ using the expression $\tau=1 / k$. The relaxation life of hydrogel 


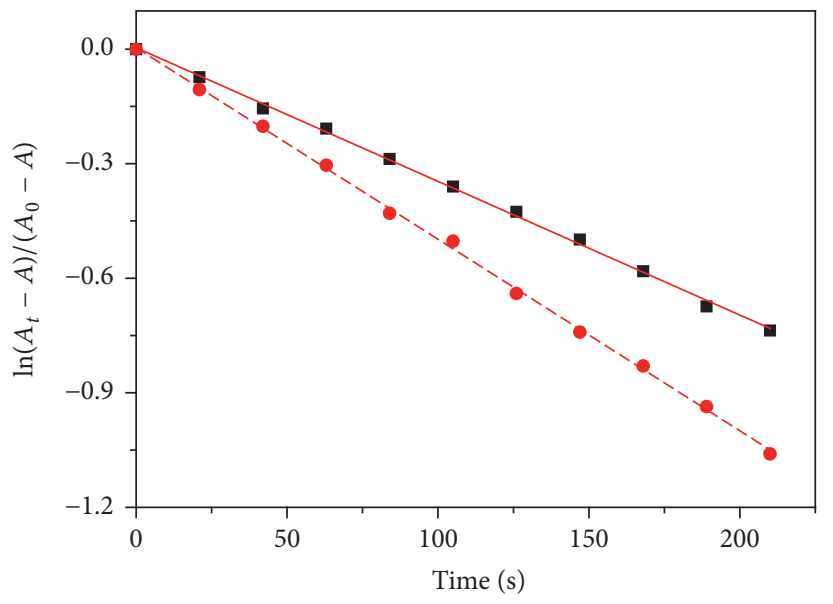

- Polymerization method

- Immersing method

Figure 5: The thermal relaxation of the MC at $\lambda_{\max }(620 \mathrm{~nm}$, immersing method; $610 \mathrm{~nm}$, polymerization method) after irradiation with a 40 W UV lamp.
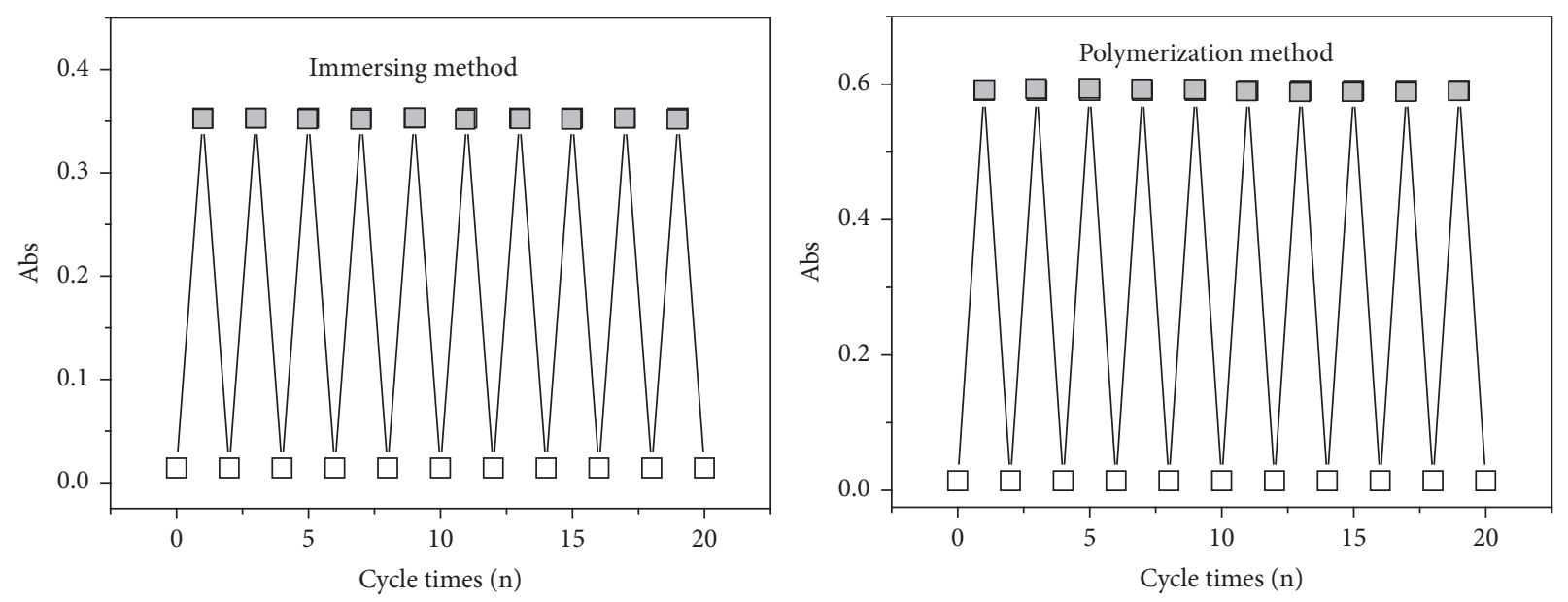

FIGURE 6: Fatigue resistance cycles of photochromic hydrogel by alternative irradiation: gray box at $\lambda=365 \mathrm{~nm}$, and white box $\lambda=632 \mathrm{~nm}$.

made by polymerization method was $289 \mathrm{~s}$ which was longer than that made by immersing method (199s); this could be assigned to the participation of SPO in polymerization reaction. As had been reported by earlier work [34], in solid resins, the bulky substituent in the vicinity of the spirooxazine moiety was benefit to the thermal fading stability of MC. For SPO in hydrogel made by polymerization method, the volume of substituent group on $9^{\prime}-\mathrm{C}$ is bigger than that made by immersing method, which depressed the large conformational change more effectively in the photochromic reaction. As a result, the thermal fading of hydrogel made by polymerization method was slower than that made by immersing method.

In further step, in order to evaluate the long-term application of photochromic properties for hydrogel, the photoinduced fatigue resistance property might be investigated by multiple irradiation cycles with UV and visible light in Figure 6. The maximum absorbances of the two photochromic hydrogels were plotted while being irradiated alternately with $365 \mathrm{~nm}$ light and $632 \mathrm{~nm}$ light. In each cycle, two photochromic hydrogels were converted to their ringclosed forms, respectively, to reach the photostationary states by irradiation with UV light $(365 \mathrm{~nm})$, and all the closedring forms were bleached by irradiation with visible light $(632 \mathrm{~nm})$. It showed that the absorbance of both hydrogels remained almost constant after 20 cycles, indicating that the main chain of copolymer as a pendant of $9^{\prime}-\mathrm{C}$ on SPO had almost no effect on the fatigue resistance. This might be because the polymer chain caused little change of $\pi$-electrons of the photomerocyanine part and the heteroaromatic part, which led to little change in ground state energy of the closedring isomers and the energy gap between the open and closed ring isomers [35].

3.3. In Vitro Drug Release Behavior. The drug loading was achieved by immersing method using different media 


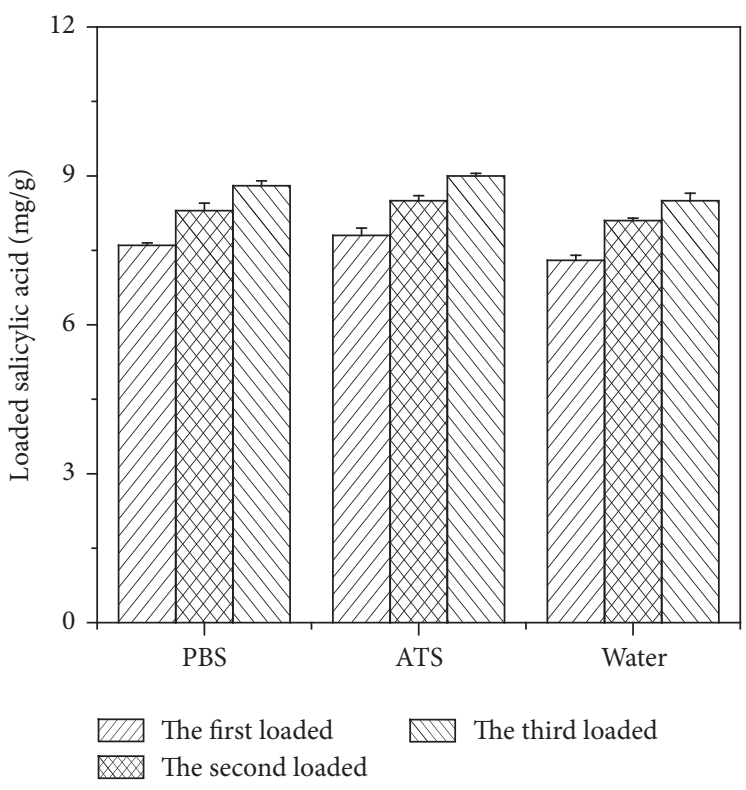

(a)

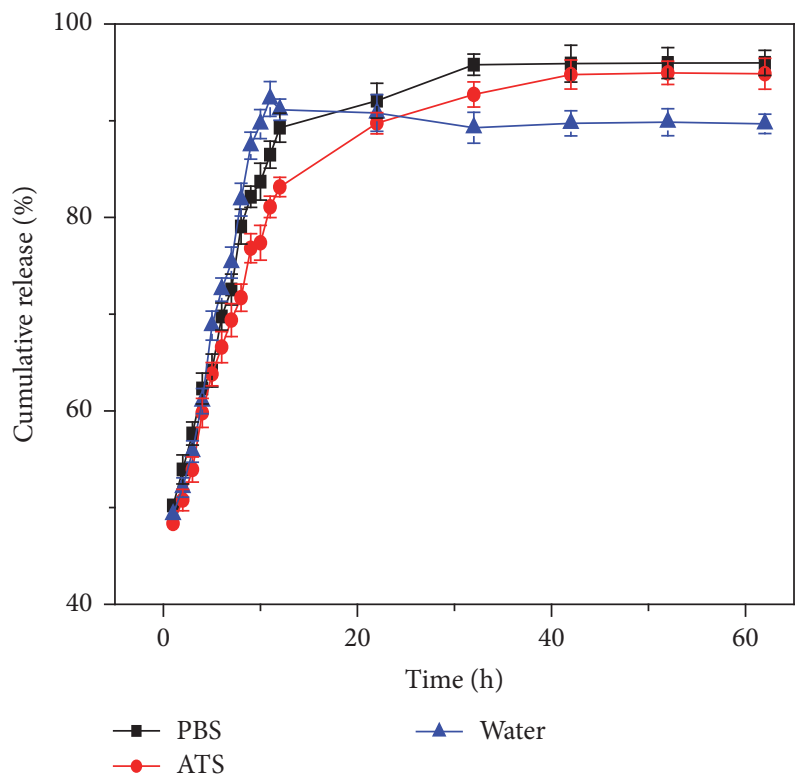

(c)

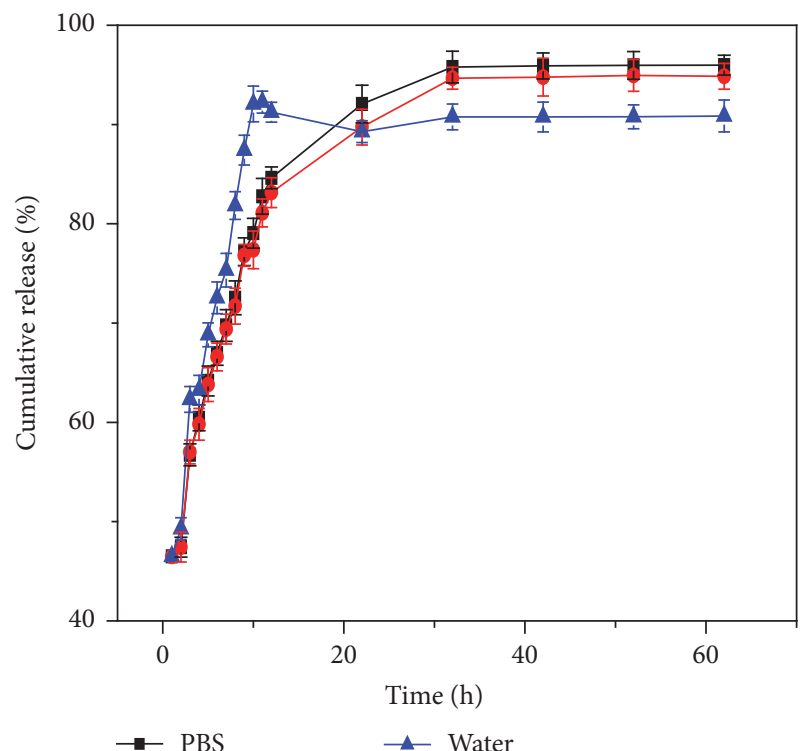

(b)

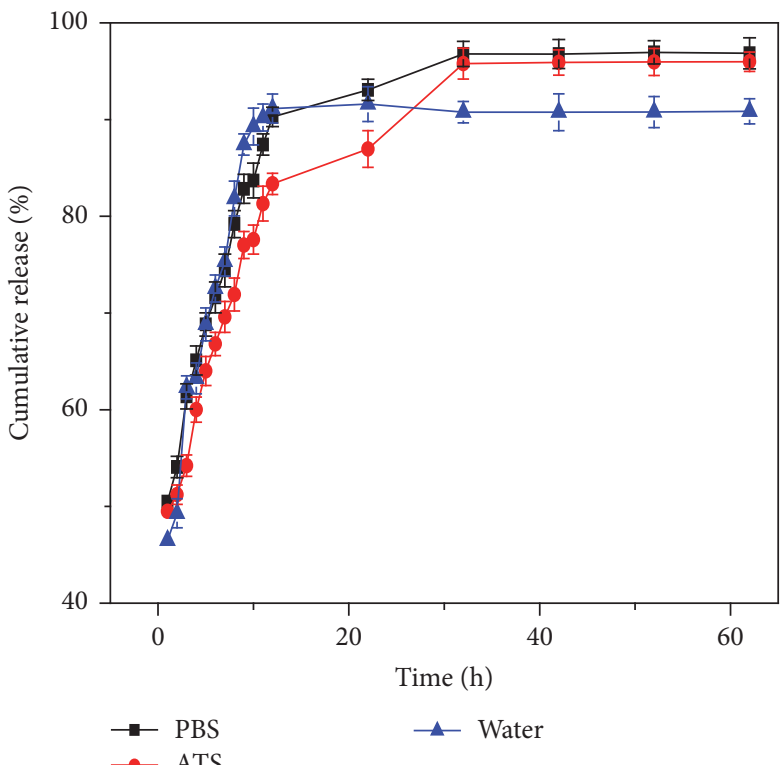

(d)

FiguRE 7: (a) Loaded salicylic acid amount in hydrogels for three times in different media, (b) salicylic acid release behavior in different media for first drug-loading, (c) salicylic acid release behavior in different media for second drug-loading, and (d) salicylic acid release behavior in different media for third drug-loading.

(Figure 7(a)). The equilibrium drug-loading amount in hydrogel was about $9 \mathrm{mg} \mathrm{g}^{-1}$. From Figure $7(\mathrm{a})$, the amount of drug incorporated in hydrogel showed slight increase with times of loading, which might be ascribed to higher drug concentration of loading solution, coming from solvent evaporation. This phenomenon indicated the hydrogel could load drugs repeatedly. Moreover, the ions in loading solution showed little influence on drug-loading amount. Theoretically, Figures 7(b)-7(d) showed the drug-releasing behavior of salicylic acid in different media. For the first time, the cumulative release rate of salicylic acid from the hydrogel was fast during $12 \mathrm{~h}$ in water, which was slow in PBS or in ATS until the release equilibrium was reached (Figure 7(b)). This difference in the cumulative release rate was reasonably attributed to salicylic acid charge screening brought by the ions in the salt solution; it caused the salicylic acid to be released slowly in PBS and ATS. For the second time, the cumulative release rate of salicylic acid was also fast in water or PBS until the release equilibrium was reached, while it was a little slower in ATS than in water (Figure 7(c)). 
For the third time, salicylic acid was released along with time in each medium (Figure $7(\mathrm{~d})$ ). It was also found that all cumulative released drug rate reached above $89 \%$ no matter the characteristics of the medium and the release time of salicylic acid. By comparing Figures $7(b)-7(d)$, the drug release profile showed the drug-releasing behavior of hydrogel in water had little difference among the used time, and it also showed faster release in PBS or ATS than the last time. One of the main reasons affecting this drug-releasing behavior was the increase of the time hydrogel submerged in the salt solution that led to increase of ions of inner hydrogel, which decreased the charge screening brought by the ions.

\section{Conclusions}

In this work, photochromic p(HEMA-NVP-SPO) hydrogel was successfully synthesized by radical polymerization, which was verified by IR spectra. Compared with pHEMA hydrogel, $\mathrm{p}$ (HEMA-NVP) copolymer hydrogel had larger equilibrium water content (EWC) and more homogenous porous structure. The formed p(HEMA-NVP-SPO) hydrogel possessed similar EWC and morphology to p(HEMA-NVP) hydrogel. The colorless $\mathrm{p}$ (HEMA-NVP-SPO) hydrogel could turn to blue after being irradiated at $365 \mathrm{~nm}$ and then recover back under visible light irradiation in $289 \mathrm{~s}$. Theoretically, the thermal fading of hydrogel made by polymerization method was slower than that made by immersing method. Additionally, the photochromic hydrogel made by polymerization method exhibited a good fatigue resistance. The drug loading is realized by immersing method. The equilibrium drugloading amount in hydrogel increased slightly with times of loading regardless of ions in solution. The sustained drug release in a given period was dependent on the characteristics of solution and loading time. The drug release profile in water showed little dependence on loading time, whereas faster release in PBS or ATS than that of the last time was detected.

\section{Competing Interests}

The authors declare that they have no potential conflict of interests regarding the publication of this article.

\section{Acknowledgments}

This work was financially supported by Research Fund for the Doctoral Program of Jinling Institute of Technology (jit-201227).

\section{References}

[1] M. Irie, T. Lifka, S. Kobatake, and N. Kato, "Photochromism of 1,2-Bis(2-methyl-5-phenyl-3-thienyl)perfluorocyclopentene in a Single-Crystalline Phase," Journal of the American Chemical Society, vol. 122, no. 20, pp. 4871-4876, 2000.

[2] Q.-L. Zhu, T.-L. Sheng, R.-B. Fu et al., "Redox-responsive photochromism and fluorescence modulation of two 3D metalorganic hybrids derived from a triamine-based polycarboxylate ligand," Chemistry-A European Journal, vol. 17, no. 12, pp. 3358-3362, 2011.
[3] Q. Zhang, J. M. Li, L. H. Niu et al., "A rapid response photochromic diarylethene material for rewritable holographic data storage," Chinese Science Bulletin, vol. 58, no. 1, pp. 74-78, 2013.

[4] D. L. Watkins and T. Fujiwara, "Bis-spironaphthooxazine based photochromic polymer materials," Journal of Materials Chemistry C, vol. 1, no. 3, pp. 506-514, 2013.

[5] E. B. Gaeva, V. Pimienta, S. Delbaere et al., "Spectral and kinetic properties of a red-blue $\mathrm{pH}$-sensitive photochromic spirooxazine," Journal of Photochemistry and Photobiology A: Chemistry, vol. 191, no. 2-3, pp. 114-121, 2007.

[6] W. Yuan, L. Sun, H. Tang et al., "A novel thermally stable spironaphthoxazine and its application in rewritable high density optical data storage," Advanced Materials, vol. 17, no. 2, pp. 156-160, 2005.

[7] D. L. Watkins and T. Fujiwara, "Synthesis, characterization, and solvent-independent photochromism of spironaphthooxazine dimers," Journal of Photochemistry and Photobiology A: Chemistry, vol. 228, no. 1, pp. 51-59, 2012.

[8] G. Berkovic, V. Krongauz, and V. Weiss, "Spiropyrans and spirooxazines for memories and switches," Chemical Reviews, vol. 100, no. 5, pp. 1741-1753, 2000.

[9] S. Kumar, D. L. Watkins, and T. Fujiwara, "A tailored spirooxazine dimer as a photoswitchable binding tool," Chemical Communications, no. 29, pp. 4369-4371, 2009.

[10] E. Herrero, N. Carmona, J. Llopis, and M. A. Villegas, "Sensitive glasslike sol-gel materials suitable for environmental light sensors," Journal of the European Ceramic Society, vol. 27, no. 16, pp. 4589-4594, 2007.

[11] A. K. Chibisov and H. Görner, "Photoprocesses in spirooxazines and their merocyanines," The Journal of Physical Chemistry A, vol. 103, no. 26, pp. 5211-5216, 1999.

[12] V. S. Marevtsev and N. L. Zaichenko, "Peculiarities of photochromic behaviour of spiropyrans and spirooxazines," Journal of Photochemistry and Photobiology A: Chemistry, vol. 104, no. 1-3, pp. 197-202, 1997.

[13] X. L. Yang, B. J. Yang, Y. Y. Liu, and H. J. Zhu, "Microwaveassisted synthesis of novel spirooxazines and their photochromic behaviors in polymer matrices," Optoelectronics and Advanced Materials-Rapid Communications, vol. 6, no. 11, pp. 1146-1152, 2012.

[14] X. Hu, L. Hao, H. Wang et al., "Hydrogel contact lens for extended delivery of ophthalmic drugs," International Journal of Polymer Science, vol. 2011, Article ID 814163, 9 pages, 2011.

[15] K. T. Nguyen and J. L. West, "Photopolymerizable hydrogels for tissue engineering applications," Biomaterials, vol. 23, no. 22, pp. 4307-4314, 2002.

[16] W. J. Seeto, Y. Tian, and E. A. Lipke, "Peptide-grafted poly(ethylene glycol) hydrogels support dynamic adhesion of endothelial progenitor cells," Acta Biomaterialia, vol. 9, no. 9, pp. 8279-8289, 2013.

[17] X. H. Hu and D. Li, "Facile way to synthesise hydrogel contact lenses with good performance for ophthalmic drug delivery," Materials Technology, vol. 28, no. 4, pp. 192-198, 2013.

[18] X. Hu, J. Qiu, H. Tan, D. Li, and X. Ma, "Synthesis and characterization of cyclodextrin-containing hydrogel for ophthalmic drugs delivery," Journal of Macromolecular Science, Part A: Pure and Applied Chemistry, vol. 50, no. 9, pp. 983-990, 2013.

[19] X. H. Hu, H. P. Tan, D. Li, and M. Y. Gu, "Surface functionalisation of contact lenses by CS/HA multilayer film to improve its properties and deliver drugs," Materials Technology, vol. 29, no. 1, pp. 8-13, 2014. 
[20] X. Gong, "Controlling surface properties of polyelectrolyte multilayers by assembly pH," Physical Chemistry Chemical Physics, vol. 15, no. 25, pp. 10459-10465, 2013.

[21] L. Zhang, X. Gong, Y. Bao et al., "Electrospun nanofibrous membranes surface-decorated with silver nanoparticles as flexible and active/sensitive substrates for surface-enhanced Raman scattering," Langmuir, vol. 28, no. 40, pp. 14433-14440, 2012.

[22] X. Hu and X. Gong, "A new route to fabricate biocompatible hydrogels with controlled drug delivery behavior," Journal of Colloid \& Interface Science, vol. 470, pp. 62-70, 2016.

[23] X. Hu, H. Tan, and L. Hao, "Functional hydrogel contact lens for drug delivery in the application of oculopathy therapy," Journal of the Mechanical Behavior of Biomedical Materials, vol. 64, pp. 43-52, 2016.

[24] X. Hu, H. Tan, X. Wang, and P. Chen, "Surface functionalization of hydrogel by thiol-yne click chemistry for drug delivery," Colloids and Surfaces A: Physicochemical and Engineering Aspects, vol. 489, pp. 297-304, 2016.

[25] X. Hu, H. Tan, P. Chen, X. Wang, and J. Pang, "Polymer micelles laden hydrogel contact lenses for ophthalmic drug delivery," Journal of Nanoscience \& Nanotechnology, vol. 16, no. 6, pp. 5480-5488, 2016.

[26] S. Wang, M.-S. Choi, and S.-H. Kim, "Bistable photoswitching in poly( $\mathrm{N}$-isopropylacrylamide) with spironaphthoxazine hydrogel for optical data storage," Journal of Photochemistry \& Photobiology A: Chemistry, vol. 198, no. 2-3, pp. 150-155, 2008.

[27] T. Kardinahl and H. Franke, "Photoinduced refractive-index changes in fulgide-doped PMMA films," Applied Physics A Materials Science \& Processing, vol. 61, no. 1, pp. 23-27, 1995.

[28] P. S. Gils, D. Ray, and P. K. Sahoo, "Designing of silver nanoparticles in gum arabic based semi-IPN hydrogel," International Journal of Biological Macromolecules, vol. 46, no. 2, pp. 237-244, 2010.

[29] M. M. Fares, S. M. Assaf, and A. A. Jaber, "Biodegradable amphiphiles of grafted poly(lactide) onto 2-hydroxyethyl methacrylate-co-N-vinylpyrrolidone copolymers as drug carriers," Journal of Applied Polymer Science, vol. 122, no. 2, pp. 840848, 2011.

[30] H. N. Al-Jallo and M. G. Jalhxoom, "Spectral correlations for $\alpha$, $\beta$-unsaturated acidhalides," Spectrochlmica Acta A, vol. 31, no. 3, pp. 265-271, 1975.

[31] X. Hu, L. Feng, W. Wei et al., "Synthesis and characterization of a novel semi-IPN hydrogel based on Salecan and poly $(\mathrm{N}, \mathrm{N}-$ dimethylacrylamide-co-2-hydroxyethyl methacrylate)," Carbohydrate Polymers, vol. 105, no. 1, pp. 135-144, 2014.

[32] S. Schneider, "Investigation of the photochromic effect of spiro [indolino-naphthoxazine] derivatives by time-resolved spectroscopy," Zeitschrift für Physikalische Chemie, vol. 154, pp. 91-119, 1987.

[33] C. Shin and H. Lee, "Effect of alkyl side-chain length and solvent on the luminescent characteristics of poly(3-nalkylthiophene)," Synthetic Metals, vol. 140, no. 2-3, pp. 177-181, 2004.

[34] R. Nakao, F. Noda, T. Horii, and Y. Abe, "Thermal stability of the spironaphthoxazine colored form in polymeric siloxanes," Polymers for Advanced Technologies, vol. 13, no. 2, pp. 81-86, 2002.

[35] T. Feczkó, O. Varga, M. Kovács, T. Vidóczy, and B. Voncina, "Preparation and characterization of photochromic poly(methyl methacrylate) and ethyl cellulose nanocapsules containing a spirooxazine dye," Journal of Photochemistry \& Photobiology A: Chemistry, vol. 222, no. 1, pp. 293-298, 2011. 

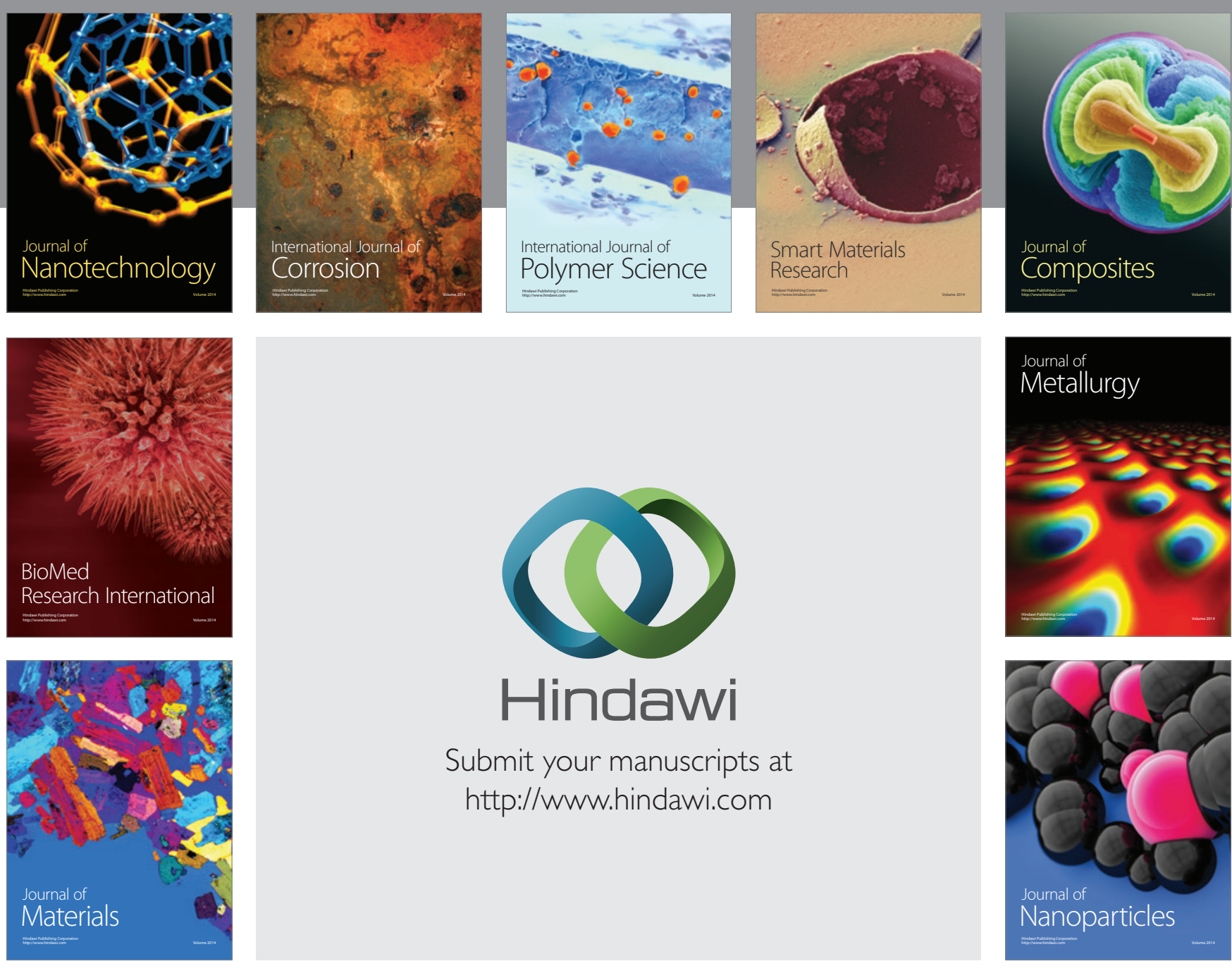

\section{Hindawi}

Submit your manuscripts at

http://www.hindawi.com

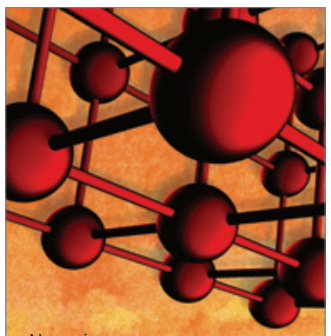

Materials Science and Engineering
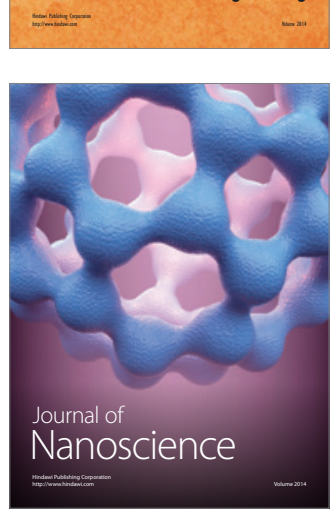
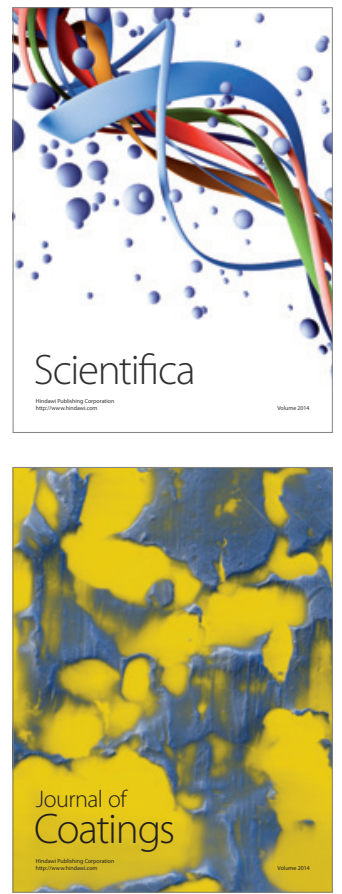
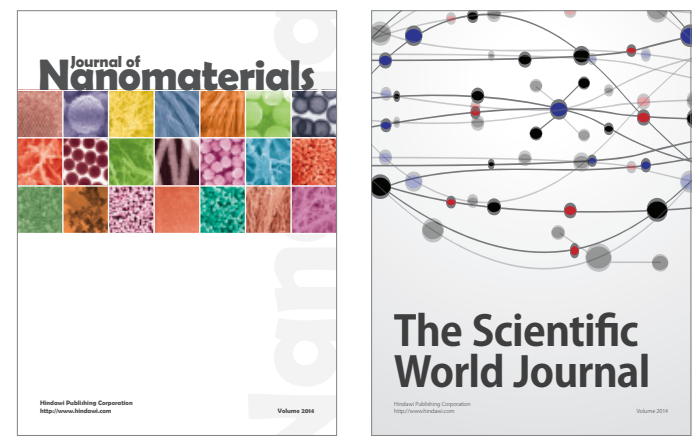

The Scientific World Journal
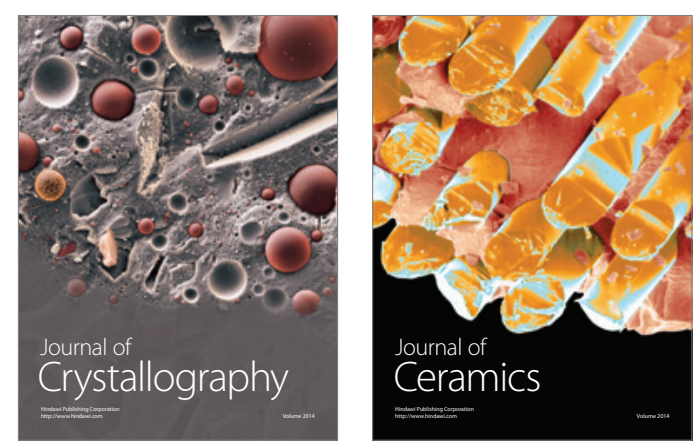
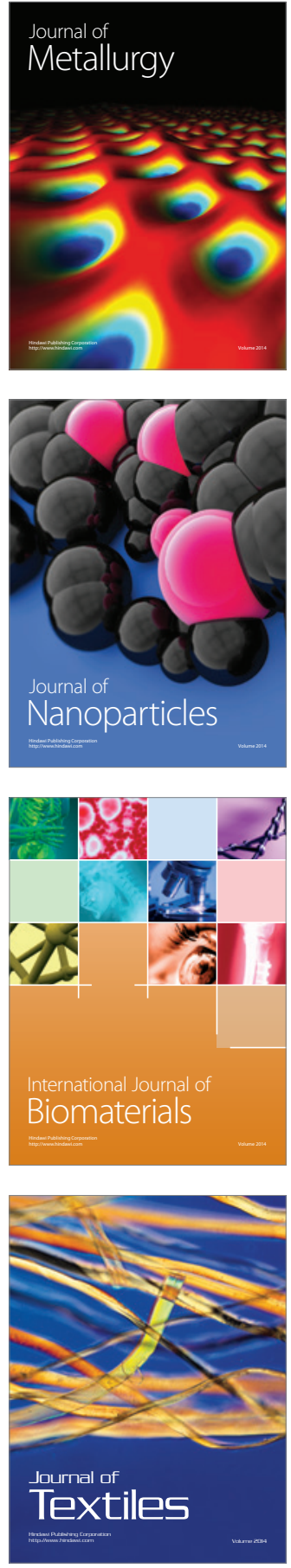